\title{
Enzymic Susceptibility of Starch from Pasta
}

\author{
P. COLONNA* $\dagger$, J.-L. BARRY†, D. CLOAREC $\dagger$, F. BORNET $\dagger$, \\ S. GOUILLOUD $\ddagger$ and J.-P. GALMICHE $\ddagger$ \\ Groupement d'Intérêt Scientifique (GIS), Nutrition Glucidique de L'Homme Sain I, \\ Place Alexis Ricordeau. 44000 Nantes, France
}

Received 16 May 1989

\begin{abstract}
The aim of this work was to study the structural factors of pasta products that are responsible for their low glucose and insulin responses and incomplete intestinal absorption of starch in healthy subjects. Native starch extracted from durum wheat in the laboratory was used as reference. Starch granules in pasta of different sizes, cooked for different time periods, were completely gelatinized, as proved by differential scanning calorimetry and X-ray diffraction. Compared to native starch, susceptibility to $\alpha$-amylase hydrolysis was always increased by cooking. Complete solubilization into oligosaccharides was obtained in $24 \mathrm{~h}$ for enzyme concentrations higher than $600 \mathrm{nkat} / \mathrm{ml}$ with $17 \mathrm{mg}$ starch per ml. Smaller pasta size and increased cooking time led to higher susceptibility. When pasta structure was destroyed by grinding, starch was solubilized completely in less than $30 \mathrm{~min}$ by $\alpha$-amylase hydrolysis. Limited swelling of starch granules during cooking and encapsulation by the protein network were partly responsible for the slow amylolysis kinetics. An estimation of the susceptibility towards $\alpha$-amylase of gelatinized starchy products is proposed, based on the minimal concentration of $\alpha$-amylase necessary to obtain the solubilization of the easily degradable fraction.
\end{abstract}

\section{Introduction}

Pasta products are made from semolina obtained from durum wheat endosperm ${ }^{1}$. Manufacture of pasta involves several steps. During mixing, water is added to semolina in order to hydrate starch and proteins. Kneading leads to a continuous gluten matrix (gliadins, glutelins and soluble proteins) entrapping starch granules, without air bubbles. At this time, starch granules are intact and the proteins are finely distributed. Extrusion is the final step and this stabilizes the gluten and gives the characteristic shape of the product. Drying is often used in order to ensure a long shelf-life for these products ${ }^{2}$. Pasta presents a unique combination of cheapness, ease of preparation, high nutritive

* To whom correspondence should be addressed. France.

$\dagger$ Institut National de la Recherche Agronomique, Rue de la Géraudière, BP 527, 44026 Nantes Cedex 03 ,

‡ Hôpital Guillaune et René Laennec, Service D'Exploration Fonctionnelle Digestive, BP 1005, Nantes Cedex, France.

Abbreviations used: $\mathrm{DSC}=$ differential scanning calorimetry; $F=$ easily-degradable fraction; $\mathrm{IBC}=$ iodine binding capacity; MAA $=$ minimal $\alpha$-amylase activity; $S W=$ water absorption; $V i=$ percentage of starch degraded in the first $5 \mathrm{~min}$ of $\alpha$-amylolysis; $V f=$ percentage of starch degraded in the last hour of $\alpha$ amylolysis. 
value and long shelf-life. Of all the major quality factors ${ }^{3}$, nutritional properties of pasta have received the least attention by researchers. Recently, nutritional investigations ${ }^{4-9}$ have demonstrated that pasta consumption leads to low glucose and insulin responses, with a slightly incomplete intestinal absorption of the starch. Therefore pasta is classified as a source of slow-release carbohydrates.

Although numerous studies have been reported on the microstructure of wheat and wheat products, very few have dealt with pasta and noodles. Scanning electron microscopy ${ }^{10.11}$ and freeze-fracturing ${ }^{12}$ techniques have been employed to investigate changes in hydrated starchy foods. With cooked spaghetti, sophisticated electron microscopy studies ${ }^{13}$ have shown completely gelatinized starch granules, entrapped in the protein network. Thereby, a contradiction is observed between their slow release character and the complete gelatinization state of the starch granules, as any heat treatment conducted with an excess of water is known to increase the availability of starch to enzymes ${ }^{14}$.

Accordingly this investigation was undertaken to understand the biochemical aspects of the nature of starch in relation to hydrolysis by $\alpha$-amylase. Two factors were studied: the size of pasta and the length of cooking time. In addition, the effect of entrapping gluten on $\alpha$-amylolysis kinetics was also investigated.

\section{Experimental}

\section{Materials}

Commercial durum wheat pasta of different sizes (spaghetti diameter $1.5 \mathrm{~mm}$, length $50 \mathrm{~mm}$; vermicelli type $1\left(v_{1}\right)$ diameter $1.1 \mathrm{~mm}$, length $30-35 \mathrm{~mm}$ and type $2\left(v_{2}\right)$ diameter $0.9 \mathrm{~mm}$, length $25-30 \mathrm{~mm}$ ) were from Panzani (Marseille, France). Potato amylose from Avebe (Veendam, Netherlands) was used as standard amylose. Semolina from durum wheat cultivar Mondur was a gift from the Laboratoire de Technologie des Céréales (Inra, Montpellier, France).

$\alpha$-Amylase (EC 3.2.1.1) from Bacillus subtilis $\left(575 \pm 19 \mathrm{nkat} / \mathrm{mg}\right.$ protein, $35^{\circ} \mathrm{C}, 1.5 \%$ waxy maize amylopectin as substrate, pH 6.9) was supplied by KochLight, Ltd (Haverhill, U.K.). Pronase from Streptomyces griseus (31 nkat $/ \mathrm{mg}$ of protein, $40^{\circ} \mathrm{C}$, bovine serum albumine as substrate, $\mathrm{pH} 7.5$ ) was supplied by Boehringer (Mannheim, West Germany).

The pasta products were ground in an IKA grinder with tap water refrigeration for not longer than $3 \mathrm{~min}$. The ground material was sieved through a $0.5 \mathrm{~mm}$ screen and coarser particles were reground until all the sample passed through a $0.5 \mathrm{~mm}$ sieve. Starch was extracted and purified from durum wheat semolina according to the procedure of Banks and Greenwood ${ }^{15}$.

\section{Chemical composition}

Moisture contents were determined by drying at $130^{\circ} \mathrm{C}$ for $2 \mathrm{~h}$. All yield and composition calculations were made on a moisture-free basis. Protein content was determined by the Kjeldhal method $(\mathrm{N} \times 5 \cdot 7)$. Starch content was evaluated as glucose by successive amyloglucosidaseglucose oxidase determination ${ }^{16}$; amylose content measurement was carried out by amperometric titration ${ }^{17}$

\section{Cooking procedure}

Samples of pasta $(10 \mathrm{~g})$ were added to boiling spring (Evian $\left.{ }^{3}\right)$ water $(200 \mathrm{ml})$, containing $0.7 \%$ $\mathrm{NaCl}$; the pasta was cooked to optimum cooking time, defined as the time required for the white 
core in the pasta strands to disappear. Time of disappearance of the core had been established in a preliminary cooking by removing strands from the cooking water at time intervals ( $1 \mathrm{~min}$ ) and crushing them between two glass plates.

Water absorption (SW) $(\%, \mathrm{~g}$ water/g dry final pasta) and cooking loss $(\%, \mathrm{~g}$ dry loss $/ \mathrm{g}$ initial dry pasta) were determined by the procedure of Mestres et $a l^{18}$.

\section{Structural studies of starch}

Wet samples were frozen in liquid nitrogen and then freeze-dried. Dry samples were analysed by $\mathrm{X}$-ray diffractometry ${ }^{19}$. DSC was performed as by Mestres et al. ${ }^{20}$.

\section{$\alpha$-Amylase hydrolysis}

Standard conditions were substrate ( $1 \mathrm{~g}$, dry basis) in $5 \mathrm{mM} \mathrm{Na}{ }^{+}$phosphate buffer $\mathrm{pH} 7.0(40 \mathrm{ml})$ and enzyme solution $(5 \mathrm{ml})$ at $35^{\circ} \mathrm{C}$. Erlenmeyer flasks were tightly stoppered and shaken vigourously. Samples $(2.5 \mathrm{ml})$ were withdrawn at predetermined time intervals and added to a mixture $(12.5 \mathrm{ml})$ of a glacial acetic acid-ethanol solution $(5: 95, \mathrm{v} / \mathrm{v})$. After $14 \mathrm{~h}$ at $3^{\circ} \mathrm{C}$, samples were centrifuged $(2500 \mathrm{r} / \mathrm{min}, 10 \mathrm{~min})$ and soluble $\alpha$-glucans were measured by successive amyloglucosidase-glucoseoxidase determination ${ }^{16}$. The extent of hydrolysis was expressed as the percentage of starch transformed into soluble oligosaccharides.

\section{Proteolytic hydrolysis}

This treatment was used prior the $\alpha$-amylolysis hydrolysis, when specified. Samples $(1 \mathrm{~g})$ were weighed with $0.1 \mathrm{mg}$ accuracy in a stoppered $250 \mathrm{ml}$ Erlenmeyer flask fitted with a magnetic bar. $0.1 \mathrm{M} \mathrm{Na}^{+}$phosphate buffer, $\mathrm{pH} 7.5(50 \mathrm{ml})$ containing $1 \%$ sodium lauryl sulfate, $1 \% 2$-mercaptoethanol $(w / v)$ and $0.02 \%$ sodium azide were added and the resulting mixture suspended by gentle magnetic stirring: samples with clumps were always discarded. Suspensions were then submitted to Pronase ${ }^{50}(1.25 \mathrm{mg} / \mathrm{ml})$ action in buffer at $40^{\circ} \mathrm{C}$ for $120 \mathrm{~min}$ with magnetic stirring. Finally the sediment was recovered by centrifugation for $15 \mathrm{~min}$ at $20000 \mathrm{~g}$.

\section{Results}

Pasta products were composed mainly of starch $(75 \cdot 7 \pm 0 \cdot 4,74 \cdot 0 \pm 0 \cdot 5$ and $73 \cdot 7 \pm 0 \cdot 7 \%$ dry basis for spaghetti, vermicelli $v_{1}$ and $v_{2}$ respectively) and proteins $(14.4 \pm 0.2$, $14.4 \pm 0.2$ and $14.3 \pm 0 \cdot 2 \%$ dry basis for spaghetti, vermicelli $v_{1}$ and $v_{2}$ respectively) (Table I).

TABLE I. Composition (\%, dry basis*) of pasta products (mean and range of duplicates)

\begin{tabular}{lccc}
\hline & & Vermicelli & Vermicelli \\
& Spaghetti & $v_{1}$ & $v_{2}$ \\
\hline Protein & $14 \cdot 4 \pm 0 \cdot 2$ & $14 \cdot 4 \pm 0.2$ & $14 \cdot 3 \pm 0.2$ \\
Starch & $75 \cdot 7 \pm 0 \cdot 4$ & $74 \cdot 0 \pm 0.5$ & $73 \cdot 7 \pm 0 \cdot 7$ \\
Amylose (\% starch) & $28 \cdot 1 \pm 1 \cdot 1$ & $27 \cdot 7 \pm 0.5$ & $26 \cdot 8 \pm 0 \cdot 4$ \\
\hline
\end{tabular}

* Mean and range of duplicates 


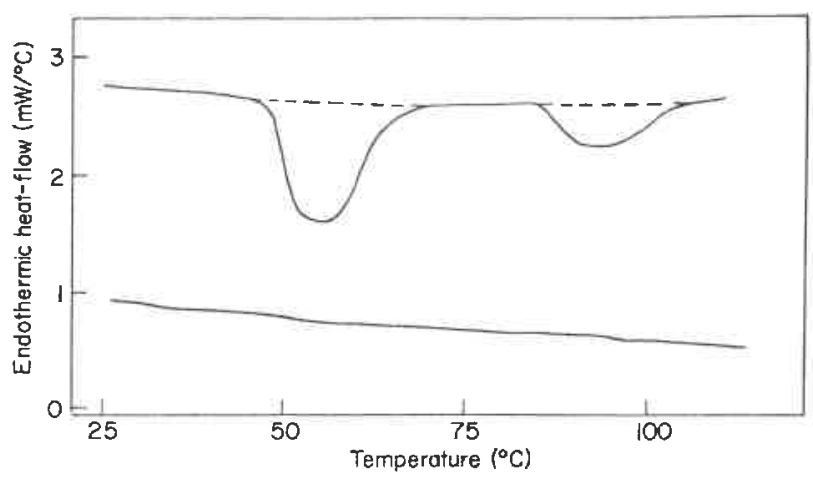

FIGURE 1. X-ray patterns of uncooked (upper curve) and cooked (10 min) (lower curve) spaghetti.

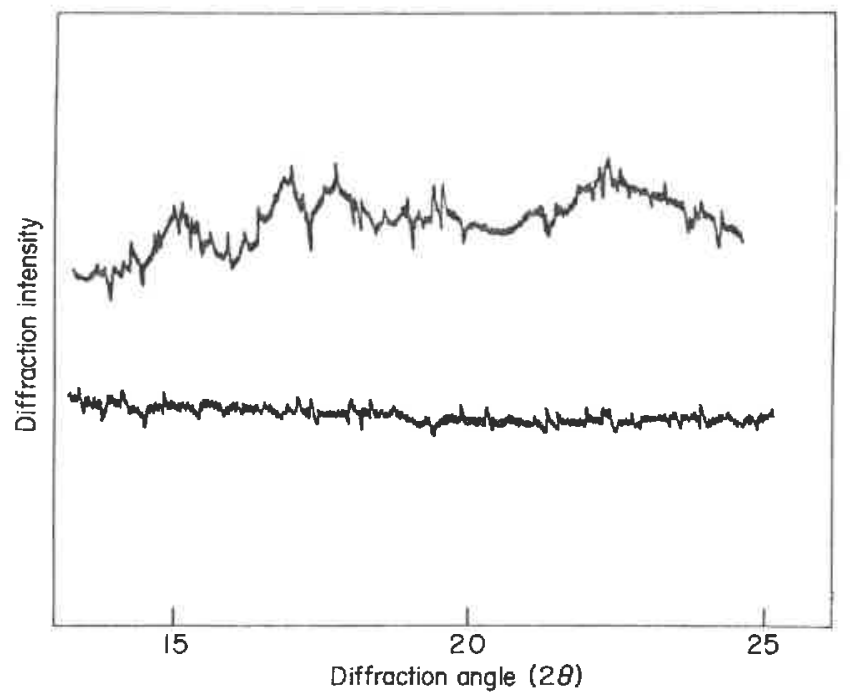

FIGURE 2. DSC thermograms of uncooked (upper curve) and cooked (10 min) (lower curve) spaghetti.

Starch in uncooked ground pasta exhibited a $X$-ray diffraction pattern with several peaks (Fig. 1) at Bragg angles (20) of 15.06, 17.98 and $23.07^{\circ}$, typical of A-type $\operatorname{starch}^{14}$. Thermal transitions of native starch in spaghetti, studied by DSC, occured at $49.5 \pm 0.5-58.1 \pm 0 \cdot 1-71 \cdot 1 \pm 0.5^{\circ} \mathrm{C}$ (enthalpy change of $6.7 \pm 0.2 \mathrm{~J} / \mathrm{g}$ ), related to the gelatinization of starch and at $86.0 \pm 0.5-95.5 \pm 0 \cdot 1-102.4 \pm 0.5^{\circ} \mathrm{C}$ (enthalpy change of $3.4 \pm 0.1 \mathrm{~J} / \mathrm{g}$ ) ascribed to the melting of amylose-lipids complexes (Fig. 2).

Starch granules were extracted and purified starting from semolina. Purified starch is highly pure $(<0.3 \%$ protein). Pure amylose extracted and purified from potato starch 
TABLE II. Cooking quality data of pasta products (mean \pm S.D. $n=4$ )

\begin{tabular}{|c|c|c|c|c|}
\hline & $\begin{array}{l}\text { Cooking } \\
\text { time }\end{array}$ & Spaghetti & $\begin{array}{c}\text { Vermicelli } \\
v_{1}\end{array}$ & $\begin{array}{c}\text { Vermicelli } \\
v_{2}\end{array}$ \\
\hline Water absorption & $T$ & $2.08 \pm 0.22$ & $2 \cdot 29 \pm 0.32$ & $2 \cdot 37 \pm 0 \cdot 28$ \\
\hline $\begin{array}{l}\text { (g water/g dry } \\
\text { final pasta) }\end{array}$ & $2 T$ & $2.63 \pm 0.31$ & $2.95 \pm 0.24$ & $2 \cdot 85 \pm 0 \cdot 17$ \\
\hline $\begin{array}{l}\text { Cooking losses } \\
\text { (g dry loss/g initial } \\
\text { dry pasta) }\end{array}$ & $\begin{array}{l}T \\
2 T\end{array}$ & $\begin{array}{l}6 \cdot 3 \pm 0 \cdot 1 \\
8 \cdot 5 \pm 0 \cdot 2\end{array}$ & $\begin{array}{r}7 \cdot 6 \pm 0 \cdot 1 \\
12 \cdot 9 \pm 0 \cdot 1\end{array}$ & $\begin{array}{r}7 \cdot 9 \pm 0 \cdot 1 \\
11 \cdot 2 \pm 0 \cdot 2\end{array}$ \\
\hline
\end{tabular}

had an iodine-binding capacity (IBC) of $21.3 \mathrm{mg} 1_{2} / 100 \mathrm{mg}$ polysaccharide. Assuming that durum wheat amylose had the same affinity, amylose content was $28 \cdot 1 \pm 1 \cdot 1 \%$. All other characteristics were identical to those observed for starch in uncooked spaghetti.

\section{Cooking transformations}

Cooking quality data for pasta products are summarized in Table II. Each type of pasta was cooked for the optimum time $(T)$ and for a double period $(2 T)$ of this time. These values are characteristic of the type of pasta: spaghetti $10 \mathrm{~min}$, vermicelli $v_{1} 7 \mathrm{~min}, \mathrm{v}_{2}$ $5 \mathrm{~min}$. Size had a major effect on water absorption (2.08 $\pm 0.22,2 \cdot 29 \pm 0.32$ and $2.37 \pm 0.28 \%$ for spaghetti, vermicelli $v_{1}$ and $v_{2}$ respectively at $T$ ). Overcooking from $T$ to $2 T$ increased the swelling index from $2.08 \pm 0.22$ to $2 \cdot 63 \pm 0.31$ in the case of spaghetti. Losses occured mainly in the first period of cooking: cooking losses represented $6.3 \pm 0.1 \%$ in the first interval ( 0 to $T$ ) and $2.2 \%$ in the second period ( $T$ to $2 T$ ) for spaghetti. The same trends were observed for vermicelli $v_{1}$ and $v_{2}$.

After cooking, neither diffraction pattern (Fig. 1) nor endothermic peak (Fig. 2) were noticed, whatever the cooking time or strand pasta size.

In order to characterize the material lost from spaghetti, cooking liquors were recovered and freeze-dried before analysis of losses. By further dissolution in $1 \mathrm{M} \mathrm{KOH}$, this lost material was analysed for its starch content by the glucoamylase method and for amylose content by the amperometric method. Losses were mainly composed of starch (63.1\% dry basis at $T$ and $61.2 \%$ at $2 T$ ). In spaghetti the IBC of the lost starch fraction increased from $7.9\left(37.0 \%\right.$ of amylose) at $10 \mathrm{~min}$ to $10.9 \mathrm{mg} I_{2} / 100 \mathrm{mg} \alpha$-glucan $(51.1 \%$ of amylose) at $20 \mathrm{~min}$. All further experiments were based on dry matter in the cooked pasta.

\section{Amylolytic studies}

To study native starch granule hydrolysis, the total amount of soluble material produced after different incubation periods was determined from $5 \mathrm{~min}$ to $4 \mathrm{~h}$ with a final measurement carried out at $24 \mathrm{~h}$.

Figure 3 shows $Y$, the percentage of soluble oligosaccharides formed as a function of time for purified starch, using an initial enzyme concentration of $600 \mathrm{nkat} / \mathrm{ml}$. $Y$ 


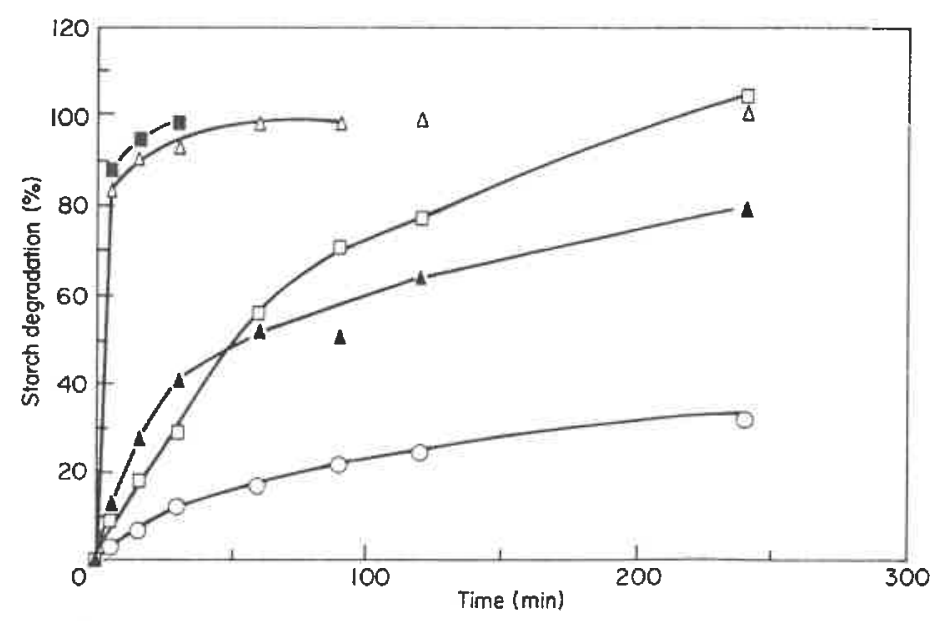

FIGURE 3. Amylolysis kinetics at $600 \mathrm{nkat} / \mathrm{ml}$ of uncooked spaghetti (A); purified starch $(O)$; cooked spaghetti $(10 \mathrm{~min})$ before $(\square)$ and after $(\triangle)$ grinding, starch paste (圆) of purified starch.

increased rapidly in the first period of hydrolysis (1-2 h); about $20 \%$ of starch was solubilized. Then the rate decreased progressively; a solubilization of $c .32 \%$ of the starch was reached in $4 \mathrm{~h}$. The easily-degradable fraction, $F$, corresponds to the extrapolation to zero time of the second linear part of the $\alpha$-amylolysis curve. $F$ was estimated to be $15 \pm 1 \%$ in native starch: this value was obtained in less than $1 \mathrm{~h}$. Starch in ground spaghetti, vermicelli $v_{1}$ and $v_{2}$ presented higher susceptibility towards $\alpha$ amylase (Table III). $V i$ corresponds to the amount of starch solubilized during the first $5 \mathrm{~min}$. $V i$ was increased up to $0.9 \pm 0.1 \%$ and $F$ to $48 \pm 1 \%$ for spaghetti. Similar observations were made for vermicelli $\mathrm{v}_{1}$ and $\mathrm{v}_{2}$ (Table III). $V f$ corresponds to the amount of starch solubilized during the last hour ( 3 and $4 \mathrm{~h}$ of hydrolysis) and was always in the range $7-9 \%$.

For intact strands of cooked spaghetti (at time $T$ ), two stages were observed in the kinetics of $\alpha$-amylolysis, using $600 \mathrm{nkat}$ of $\alpha$-amylase $/ \mathrm{ml}$ in a rapid initial stage (60 min) $60-72 \%$ of starch was solubilized: no significant variation of $V i$ was noticed. Then in a slow final stage, $\alpha$-amylase caused a complete starch solubilization in $24 \mathrm{~h} . F$ was estimated to be $64 \pm 1 \%$ total starch. If higher concentrations of $\alpha$-amylase were used, neither degradation rate nor $F$ were increased. Higher values of $F$ were obtained at $T$ for vermicelli $\mathrm{v}_{1}(72 \pm 2 \%)$ and $\mathrm{v}_{2}(85 \pm 3 \%)$.

Overcooking increased $F$ slightly up to $66 \pm 1 \%$ starch (Table III). With strands of vermicelli $v_{1}$ and $v_{2}$, the same tendancies were observed. $F$ represented $73 \pm 2 \%$ and $85 \pm 2 \%$ total starch for strands of vermicelli $v_{1}$ and $v_{2}$ respectively cooked for $2 T$.

Whatever the cooking time, hydrolysis for $24 \mathrm{~h}$ using $\alpha$-amylolysis at $600 \mathrm{nkat} / \mathrm{ml}$ led to complete solubilization of starch as oligosaccharides.

When ground, cooked spaghetti presented a very rapid hydrolysis; more than $92 \%$ of starch was solubilized in $30 \mathrm{~min} . F$ represented $97 \pm 3 \%$ of initial starch. No difference was noticed between the pasta after grinding, whatever the strand size or cooking time. 
TABLE III. $\alpha$-Amylolysis characteristics of pasta products (means \pm S.D., $n=3$ )

\begin{tabular}{|c|c|c|c|}
\hline & $\begin{array}{c}V i \\
\text { (\% starch } \\
\text { in } 5 \mathrm{~min})\end{array}$ & $\begin{array}{c}V f \\
\text { (\% starch } \\
\text { in } 60 \mathrm{~min})\end{array}$ & $\begin{array}{c}F \\
(\% \text { starch })\end{array}$ \\
\hline \multicolumn{4}{|l|}{ Spaghetti } \\
\hline Uncooked & $0 \cdot 9 \pm 0 \cdot 1$ & $7.5 \pm 0.2$ & $48 \pm 1$ \\
\hline Cooked $T$ & $1 \cdot 0 \pm 0 \cdot 1$ & $14 \cdot 1 \pm 0 \cdot 1$ & $64 \pm 1$ \\
\hline Cooked $2 T$ & $1 \cdot 1 \pm 0 \cdot 1$ & $14 \cdot 1 \pm 0 \cdot 1$ & $66 \pm 1$ \\
\hline $\begin{array}{l}\text { Cooked } T \text { and } \\
\text { ground }\end{array}$ & $85 \cdot 8 \pm 3 \cdot 9$ & $3 \cdot 3 \pm 0 \cdot 5$ & $97 \pm 3$ \\
\hline \multicolumn{4}{|l|}{ Vermicelli $v_{1}$} \\
\hline Uncooked & $0.9 \pm 0.1$ & $9 \cdot 1 \pm 0 \cdot 2$ & $48 \pm 1$ \\
\hline Cooked $T$ & $1.5 \pm 0.2$ & $12 \cdot 2 \pm 0 \cdot 1$ & $72 \pm 2$ \\
\hline Cooked $2 T$ & $1 \cdot 5 \pm 0 \cdot 1$ & $14 \cdot 9 \pm 0 \cdot 1$ & $73 \pm 3$ \\
\hline \multicolumn{4}{|l|}{ Vermicelli $\mathrm{v}_{2}$} \\
\hline Cooked $T$ & $1.9 \pm 0.2$ & $13.8 \pm 0.1$ & $85 \pm 3$ \\
\hline Cooked $2 T$ & $1.9 \pm 0.1$ & $13.8 \pm 0.1$ & $85 \pm 2$ \\
\hline Native starch & $0 \cdot 4 \pm 0 \cdot 1$ & $4 \cdot 2 \pm 0.8$ & $15 \pm 1$ \\
\hline
\end{tabular}

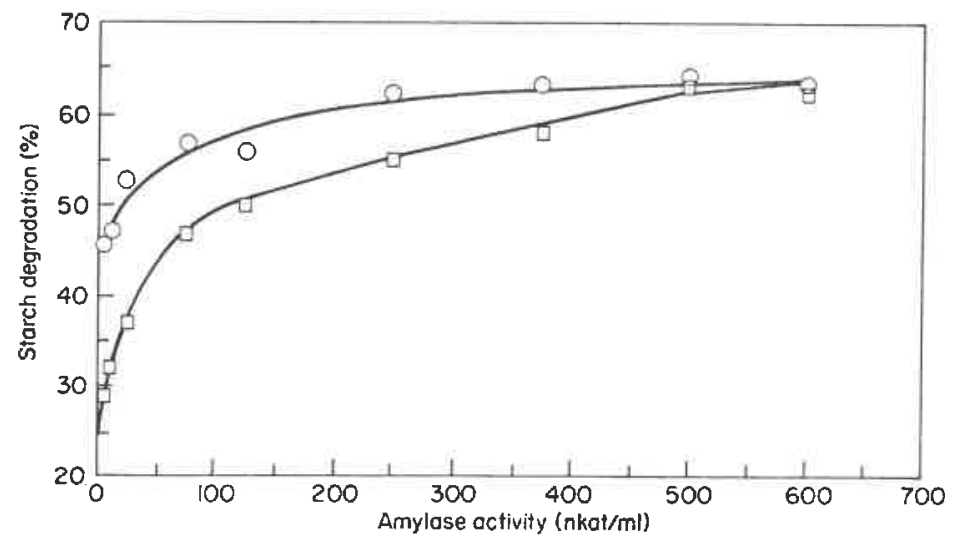

FIGURE 4. Variation of $F$ as a function of total $\alpha$-amylase activity for spaghetti ( $\square$ ) and deproteinised spaghetti $(O)$ cooked for $10 \mathrm{~min}$.

In all intact strands of cooked pasta the amount of starch solubilized in $1 \mathrm{~h}$ was of the same magnitude as $F$. The variation of this fraction, as a function of the activity of $\alpha$ amylase present in the hydrolysis flask (Fig. 4), was studied on cooked spaghetti (T). A minimal activity of $500 \mathrm{nkat} / \mathrm{ml}$ was found to be necessary for maintaining $F$ at its value of 64. Overcooking (time $2 T$ ) decreased this value to $90 \mathrm{nkat} / \mathrm{ml}$. The same tendency was observed for vermicelli $v_{1}$ and $v_{2}$, but with lower $\alpha$-amylase limit concentrations. Whereas 400 and $270 \mathrm{nkat} / \mathrm{ml}$ were necessary for $v_{1}$ and $v_{2}$ respectively cooked at $T$, only 190 and $90 \mathrm{nkat} / \mathrm{ml}$ respectively were needed when $v_{1}$ and $v_{2}$ were cooked for $2 T$. 


\section{Effect of gluten}

The activity of the $\alpha$-amylase preparation used was checked as a function of gluten added to the solution. To $3 \mathrm{ml}$ of a waxy maize starch paste $(1.5 \%)$ were added from 0 to $1.5 \mathrm{ml}$ of a gluten suspension $(1.5 \%$ ). The volume was made up to $4.5 \mathrm{ml}$ with water and the gluten suspension was boiled for $10 \mathrm{~min}$. In the concentration range of $0-0.66 \mathrm{mg}$ gluten $/ \mathrm{ml}, \alpha$-amylase still had the same activity of $575 \pm 21 \mathrm{nkat} / \mathrm{mg}$ of protein.

Protein removal from the cooked pasta was carried out using Pronase on intact strands of cooked pasta. No starch was lost during this step, as proved by a negative iodine reaction of the supernatant and the absence of glucose by the glucose oxidase test.

Spaghetti samples in which proteins had been removed, were submitted immediately to $\alpha$-amylolysis. The amount of starch degraded in $1 \mathrm{~h}$ was followed as a function of $\alpha$ amylase activity added in the hydrolysis reaction flask. Protein removal resulted in a more rapid solubilization of starch (Fig. 4).

\section{Starch gelatinization}

Purified starch from durum wheat had been submitted to thermal dispersion for $10 \mathrm{~min}$ at a concentration of $4 \%$ without shearing, by using boiling water and bubbling $\mathrm{N}_{2}$. Swelling and solubilization phenomena represented $31.1 \mathrm{~g} \mathrm{H}_{2} \mathrm{O} / \mathrm{g}$ dry sediment and $37.6 \%$ of solubilized starch respectively. This starch suspension was completely solubilized into oligosaccharides in $30 \mathrm{~min}$ using an $\alpha$-amylase activity of $600 \pm 15$ nkat $/ \mathrm{ml}$.

In order to gelatinize starch in restricted swelling and solubilization conditions, starch granules were gelatinized by immersing flasks containing moistened starch into boiling water for $30 \mathrm{~min}$. Moisture content had been adjusted from 2.5 to $7.0 \mathrm{~g} \mathrm{H}_{2} \mathrm{O} / \mathrm{g}$ dry starch. Complete starch gelatinization was demonstrated by the absence of an X-ray diffraction pattern. Immediately after heating, treated samples were submitted to a usual $\alpha$-amylolysis $(600 \mathrm{nkat} / \mathrm{ml})$ by addition of the phosphate buffer and enzyme solution. Starch solubilization proceded quickly in the first hour up to $75 \%$; after that, the rate decreased progressively, leading to complete solubilization in $25 \mathrm{~h}$. Few differences were noticed between the samples varying in starch/water ratio during processing (Fig. 5). $47-63 \%$ of starch were solubilised in the first $5 \mathrm{~min}$. Whereas $F$ values were in the range $72-88 \%, V f$ were about $3 \cdot 8$. However samples treated in high moisture conditions were slightly more susceptible than those heated with low moisture content.

\section{Discussion}

The composition of the pasta products corresponded to those published in the literature. Starch was extracted and purified from semolina rather than from uncooked spaghetti, because the latter had a tough texture, preventing any disintegration without starch damage. This purified starch was less susceptible to $\alpha$-amylase than starches from pasta, which all had the same suceptibilities. Starch from durum wheat showed characteristics in good agreement with the results of Dexter and Matsuo ${ }^{21}$ and Klasson and Hill ${ }^{22}$. The amylose content was lower than for mung bean noodles. In this latter case, the high 


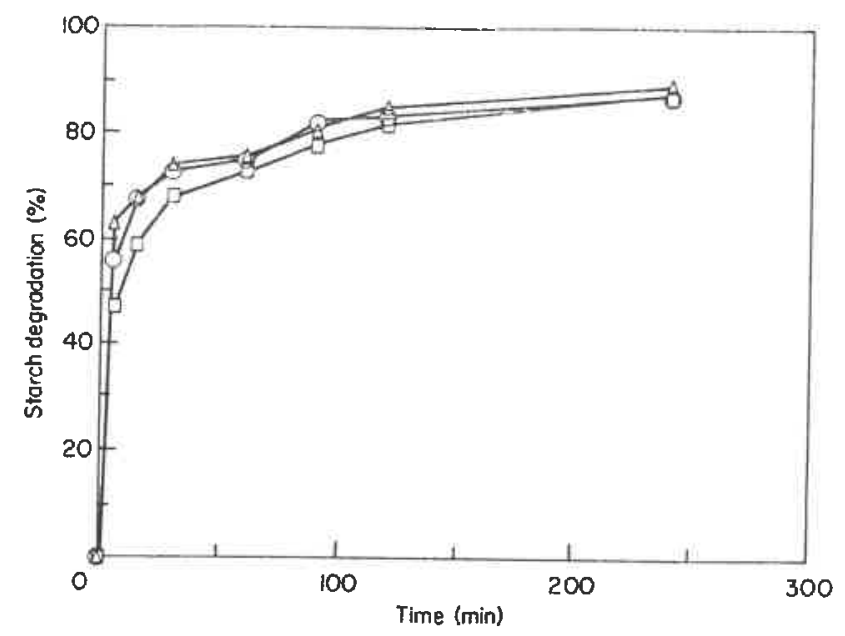

FIGURE 5. Amylolysis kinetics at $600 \mathrm{nkat} / \mathrm{ml}$ of durum wheat starch heat-treated with $2.0(\square), 5.0(\mathrm{O})$ and $7.0(\triangle) \mathrm{g}$. $\mathrm{H}_{2} \mathrm{O}$ per $\mathrm{g}$ dry starch for $10 \mathrm{~min}$.

amylose content $(32 \%)^{18}$ has been shown to be responsible for the slow release character of the mung bean noodles, as amylose is present as a gel.

Cooking losses were measured and were taken into account for calculations on $\alpha$ amylase kinetics. Starch losses were composed mainly of amylose. This corresponds to the usual leaching of amylose when starch granules are pasted as observed for wheat ${ }^{23}$ and legume ${ }^{16}$ starches. With spaghetti cooked at $T$ and $2 T$, the loss of amylose led to an apparent amylose content of 27.6 and $26.4 \%$ total starch respectively for the starch fraction remaining in the pasta; this difference is insignificant. Although cooking is a continuous operation, most of the cooking losses occured in the first period of cooking; overcooking led mainly to a higher swelling by water absorption. As expected, each pasta size proved to absorb more water and lost more material when cooking time increased. So cooked pasta presented a large range of water absorption from 2.08 to $2.95 \mathrm{~g}$ water/g dry pasta. These characteristics have to be compared to the behaviour of starch granules when pasted in the same conditions (cooking water, temperature, time) as for cooking of pasta. It appeared that starch granules entrapped in the pasta were less soluble and less swollen.

Starch was completely gelatinized after cooking, whatever the cooking time or pasta strand size. With purified starch gelatinized in an excess of water (pasting), degradation was rapid. The same behaviour was obtained with ground, cooked pasta.

However cooked pasta, when studied as intact strands, presented a degradation rate far slower than when ground. The surface areas of cooked strand were not determined, due to the lack of an adequate experimental procedure. However the smallest pasta strands, $v_{2}$, should have a relatively higher surface: weight ratio than $v_{1}$ and spaghetti. In in vivo situations, chewing led to disintegration, on which no adequate experimental procedure is available at the present time. Factors involved in the slow hydrolysis of intact cooked pasta were investigated. Inhibition of $\alpha$-amylase by gluten has to be 
discarded as the explanation because gluten had no effect on $\alpha$-amylase activity in the range of 1-5 mg gluten protein $/ \mathrm{ml}$. However gluten caused an encapsulation of swollen starch granules. Removal of protein by Pronase increased the degradation rate whatever the size or cooking time. Recently, high temperature drying has become more usual in the pasta industry, 24. As mainly proteins should be transformed in these conditions $^{25}$, a high level of protein crosslinking would be obtained, leading to a more intense encapsulation of starch, thus decreasing its susceptibility. Such starch-gluten interactions have been also shown to be responsible for the low plasma responses observed by Holm et al..$^{26}$ and by Jenkins et al. ${ }^{27}$ for heat-treated wheats and breads, respectively. In their experiments, they used gluten-free breads. The absence of gluten prevented the protein network formation. But it should have also modified the gelatinisation behaviour of starch, in terms of swelling and solubility, enabling a gelatinisation pattern similar to the one observed in pure water. Secondly, bread texture results from an air-expansion inside the dough, with a disruption of the protein network, whereas in pasta the gluten network is only submitted to the swelling of starch granules during cooking. Therefore their experiments and findings are hardly applicable to pasta.

Nevertheless, $\alpha$-amylolysis kinetics obtained with such deproteinized pasta were still lower than the one of starch pasted in an excess of water. Restricted swelling of starch granules during cooking can be invoked. Experiments on gelatinization in limited amounts of water were conducted: complete gelatinization was checked by the absence of X-ray diffraction pattern. Degradation rates of such gelatinized starches were lower than the one resulting from gelatinization in excess of water. This explanation is confirmed by the effect of overcooking and pasta size. In our results, swelling presented a higher influence on the restriction of starch susceptibility than did pasta size. Therefore, lower concentrations of $\alpha$-amylase were necessary to obtain the same level of degradation. The physical basis of this second factor is the limitation of $\alpha$-amylase diffusion, as already observed in amylose and amylopectin gels for protein diffusion ${ }^{28}$.

During this experimental work, characterization of gelatinized starch structures by DSC or X-ray diffraction failed to find any difference between the samples. Enzymic degradation kinetics did not discriminate among different samples when $\alpha$-amylase activity was present in a large excess. Unfortunately, most studies on enzymic hydrolysis which are published in the literature either did not report the influence of enzymic activity ${ }^{27,29-31}$ or did not check that $\alpha$-amylase activity was not the limiting factor ${ }^{32-34}$. In this investigation an experimental procedure for the discrimination among gelatinized starch samples is the determination of the minimal activity of $\alpha$-amylase (MAA) necessary to accomplish the solubilization of the easily-degradable fraction in less than 1 hour. This procedure is different from the determination of the resistant starch fraction ${ }^{35}$, for which complex enzymic protocols, involving several enzymes, are used. In the present work, the starch was always completely degradable, the differences being in the degradation rates. The procedure used here permits discrimination among samples of completely gelatinized starches. The MAA of cooked pasta were well correlated with the swelling indices of the same samples before hydrolysis: MAA $=133 \cdot 6-42 \cdot 68 * \mathrm{SW}$ with a correlation coefficient of $0.862(n=12)$. Further work is in progress to model the hydrolysis rate of swollen starchy structures.

These in vitro results give physicochemical basis for the in vivo results of Bornet $e t$ al.$^{9}$ 
Three main factors would explain the slow release character of pasta: the large particle size of pasta strands, the starch encapsulation by gluten and the limited water absorption of the starch. In vitro results ${ }^{9}$ demonstrated that pasta products are completely degradable into oligosaccharides. However, due to the transit time, a small fraction of starch should arrive in the large intestine, leading to malabsorption of pasta in the small bowel. This malabsorption has been estimated at less than $4 \%{ }^{9}$ and is not related to a limiting factor of starch intestinal absorption. Comparisons have been made by several authors ${ }^{33,36-39}$ between hydrolysis in vitro by amylases and in vivo studies of postprandial glucose and insulin response in adult human, pig or rabbit. They often presented good correlations, nevertheless the in vitro results generally present a quantitative difference in the magnitude of the responses for various starch samples. Therefore, such results should be valuable mainly for food technologists, in the development of starchy foods with slow release carbohydrate characteristics.

This investigation was supported by a grant Physiologie de la digestion des glucides awarded by the Ministère de la Recherche et de I Enseignement Supérieur, Paris, France.

The authors are very grateful to Geneviève Compoint for her excellent technical assistance and to Alain Buléon for $\mathrm{X}$-ray diffraction experiments.

\section{References}

1. Antonelli, I. J. Food Technol. 15 (1980) 125-145.

2. Dexter, J. E., Matsuo, R. R. and Morgan, B. C. J. Food Sci. 46 (1981) 1741-1746.

3. Feillet, P. Ann. Nutr. Diet 12 (1977) 299-310.

4. Anderson, I. H., Levine, A. S. and Levitt, M. D. N. Engl. J. Med. 304 (1981) 891-892.

5. Jenkins, D. J. A., Wollever, T. M. S., Taylor, R. H., Baker, H., Fielden, H., Baldwing, J. M., Bowling, A. C., Newman, H. C., Jenkins, A. L. and Goff, D. V. Am. J. Clin. Nutr. 34 (1981) 362-366.

6. Jenkins, D. J. A., Wollever, T. M. S., Jenkins, A. L., Lee, R., Wong, G. S., and Josse, R. Diabetes Care $6(1983) 155-159$.

7. Levitt, M. D., Hirsch, P., Fetzer, A., Sheahan, M. and Levine, A. S. Gastroenterology 92 (1987) 383-389.

8. Bornet, F. R. J., Costagliola, D., Riskalla, S., Blayo, A., Fontvielle, A. M., Haardt, M. J., Letanoux, M., Tchobroutsky, G. and Slama, G. Am. J. Clin. Nutr. 45 (1987) 595-98.

9. Bornet, F. R. J., Cloarec, D., Barry, J. L., Colonna, P., Gouilloud, S., Delort-Laval, J. and Galmiche, J.-P. Am. J. Clin. Nutr. 50 (1989) 315-323.

10. Dexter, J. E., Dronzek, B. L. and Matsuo, R. R. Cereal Chem. 55 (1978) 23-30.

11. Dexter, J. E. and Matsuo, R. R. Cereal Chem. 56 (1979) 202-208.

12. Cloke, J. D., Gordon, J. and Davis, E. A. Food Microstructure 2 (1982) 177-187.

13. Pagani, M. A., Gallant, D. J., Bouchet, B. and Resmini, P. Food Microstructure 5 (1986) 111-129.

14. French, D. in 'Starch: Chemistry and Technology' (R. L. Whistler, J. N. Bemiller and E. F. Paschall, eds.), 2nd edn, Academic Press, London and New York (1984) pp 183-247.

15. Banks, W. and Greenwood, C. T. 'Starch and its Components', Edinburgh University Press, Edinburgh (1975) pp 5-7.

16. Colonna, P. and Mercier, C. Phytochemistry 24 (1985) 1667-1674.

17. Larson, B. L., Gilles, K. A. and Jennes, R. Anal. Chem. 25 (1953) 802-804.

18. Mestres, C., Colonna, P. and Buleon, A. J. Food Sci. 53 (1989) 1809-1813.

19. Buleon, A., Bizot, H., Delage, M. M. and Multon, J. L. Starch 34 (1982) 361-366.

20. Mestres, C., Colonna, P. and Buleon, A. J. Cereal Sci. 7 (1988) 123-134.

21. Dexter, J. E. and Matsuo, R. R. J. Food Sci. 56 (1979) 190-195.

22. Klassen, A. J. and Hill, R. D. Cereal Chem. 48 (1971) 647-654. 
23. Doublier, J. L. Starch 33 (1981) 415-420.

24. Jeanjean, M. F., Damuidaux, R. and Feillet, P. Cereal Chem. 57 (1980) 325-331.

25. Resmini, P. and Pagani, M. A. Food microstructure 2 (1983) 1-12.

26. Holm, J., Bjorck, I., Asp, N. G., Sjoberg, L. B. and Lundquist, I. J. Cereal Sci. 3 (1985) 193-206.

27. Jenkins, D. J. A., Thorne, M. J., Wolever, T. M. S., Jenkins, A. L., Rao, A. V. and Thompson, L. U. Am. J. Clin. Nutr. 45 (1987) 946-951

28. Leloup, V. M., Colonna, P. and Ring, S. G. Food Hydrocolloids 1 (1987) 465469.

29. Englyst, H. and Cummings, J. H. Am. J. Clin. Nutr. 44 (1986) 42-50.

30. Englyst, H. and MacFarlane, G. T. J. Sci. Food. Agric. 37 (1986) 699-706.

31. Siljestrom, M., Bjorck, I., Eliasson, A.-C., Lonner, C., Nyman, M. and Asp, N-G. Cereal Chem. 65 (1988) $1-8$.

32. Snow, P. and O'Dea, K. Am. J. Clin. Nutr. 34 (1981) 2721-2727.

33. Bjorck, I., Asp, N.-G., Birkhed, D., Eliasson, A.-C., Sjoberg, L.-B. and Lundquist, I. J. Cereal Sci. 2 (1984) 165-178.

34. Bjorck, I., Nyman, M., Pedersen, B., Siljestrom, M., Asp, N.-G. and Eggums, B. O. J. Cereal Sci. 4 (1986) $1-11$.

35. Bjorck, I., Nyman, M., Pedersen, B., Siljestrom, M., Asp, N.-G. and Eggums, B. O. J. Cereal Sci. 6 (1987) 159-172.

36. Lee, P. C., Brooks, S. P., Kim, O., Heitlinger, L. A. and Lebenthal, E. J. Nutr. 115 (1985) 93-103.

37. Bjorck, I., Asp, N. G., Birkhed, D. and Lundquist, I. J. Cereal Sci. 2 (1984) 91-103.

38. Jenkins, D. J. A., Ghafari, H., Wolever, T. M. S., Taylor, R. H., Jenkins, A. L., Barker, H. M., Fielden, H. and Bowling, A. C. Diabelologia 22 (1982) 450-455.

39. O'Dea, K., Snow, P., and Nestel, P. Am. J. Clin. Nutr. 34 (1981) 1991-1993. 